\title{
Pharmacokinetic Studies of Baclofen Are Not Sufficient to Establish an Optimized Dosage for Management of Alcohol Disorder
}

\author{
Nicolas Simon ${ }^{1 *}$, Nicolas Franchitto ${ }^{2}$ and Benjamin Rolland ${ }^{3,4}$ \\ ${ }^{1}$ Aix Marseille Univ, INSERM, IRD, SESSTIM, Hop Sainte Marguerite, Service de Pharmacologie Clinique, CAP, Marseille, \\ France, ${ }^{2}$ Service d'addictologie, Centre Hospitalier Universitaire de Toulouse, Institut National de la Santé et de la Recherche \\ Médicale (INSERM) UMR 1027, Université Paul Sabatier, Toulouse, France, ${ }^{3}$ Service Universitaire d'Addictologie, Pôle \\ UP-MOPHA, CH Le Vinatier, Bron, France, ${ }^{4}$ Univ Lyon, Inserm U1028, CNRS UMR5292, UCBL, CRNL, Bron, France
}

OPEN ACCESS

Edited by:

Renaud de Beaurepaire, Groupe Hospitalier Paul Guiraud (GHPG), France

Reviewed by: Kirsten Morley,

University of Sydney, Australia Robert L. Kriel,

University of Minnesota, United States

*Correspondence: Nicolas Simon nicolas.simon@ap-hm.fr

Specialty section: This article was submitted to Addictive Disorders,

a section of the journal

Frontiers in Psychiatry

Received: 25 May 2018 Accepted: 17 September 2018

Published: 05 October 2018

Citation:

Simon N, Franchitto $N$ and Rolland $B$ (2018) Pharmacokinetic Studies of

Baclofen Are Not Sufficient to Establish an Optimized Dosage for Management of Alcohol Disorder.

Front. Psychiatry 9:485.

doi: 10.3389/fpsyt.2018.00485
Several clinical randomized trials have evaluated the interest of baclofen in patients with alcohol use disorder. Depending on the study design and the inclusion criteria, the results vary from enthusiastic to pessimistic. However, all researchers and practitioners agree that they observe a wide variability in the therapeutic responses. If some patients exhibit a clinical response at low doses, $\sim 40 \mathrm{mg}$ daily, others require doses higher than $300 \mathrm{mg}$. Before multiplying new other clinical trials, it is required to better understand the reason of this variability. Several mechanisms may be responsible for providing different effects with an identical daily dose. Especially, each pharmacokinetic step, absorption, distribution, metabolism, and elimination may lead to a different exposure after an identical dose. Absorption may imply a saturation process limiting the bioavailability $(F)$ of baclofen in some patients. In such a situation, food, or drug-drug interaction can change the absorption rate of the drug modifying the maximum concentration (Cmax) and area under the curve (AUC). Distribution and brain penetration across the blood-brain barrier may depend of a specific transporter. These transporters are subject to genetic polymorphism and drug-drug interaction. Finally, elimination may be increased by a specific secretion pathway. This review describes all available pharmacokinetic data on these different pharmacokinetics steps aiming to identify the source of variability of baclofen in patients with alcohol use disorder.

Keywords: clinical pharmacokinetics, baclofen, alcohol use disorder, modeling, GABA

\section{INTRODUCTION}

Baclofen is a racemic drug with GABA-B receptor agonist properties. It is widely prescribed as a spasmolytic agent to treat spasticity caused by central nervous system lesions or dysfunction (1). For several years baclofen has been prescribed off-label in Alcohol Use Disorder (AUD) patients to prevent relapse or to reduce drinking (2). This new indication is even authorized in France as "temporary recommendation for use." Unfortunately, the use of this compound is made difficult by the lack of knowledge on prescription guidelines, dosage and characteristics of patients with the highest probability of a clinical response $(2,3)$. In clinical practice, a wide inter-individual variability of dose required to obtain an effect is often described from 30 up to $300 \mathrm{mg}$ per day (2). Curiously, randomized clinical trials have been performed before full evaluation 
of pharmacokinetic properties and even a clear pharmacodynamic proof of concept. This lack of a standard clinical drug development in this new indication may explain the discrepancy between clinical trials (4-7). Thus, the aim of this review is to recapitulate the pharmacokinetic properties already reported and to identify the studies required to optimize its evaluation in this new indication.

\section{ABSORPTION}

Only oral formulation with an immediate release is currently available. In healthy volunteers the time to reach the peak concentration in plasma after administration (Tmax) varied between $1 \mathrm{~h}(8)$ and $2.79 \mathrm{~h}(9)$. Other pharmacokinetic studies in healthy volunteers found similar results: $1.13 \mathrm{~h}(10), 1.2 \mathrm{~h}$ (11), or $2 \mathrm{~h}(12,13)$. The pharmacokinetic studies performed in AUD patients have been realized in real life conditions. Such studies used sparse sampling instead of full profiles, which did not allow a direct observation of Tmax. Meanwhile a formula (Equation 1) can be used for computing Tmax from the constant of absorption (Ka) and the constant of elimination (Ke). The calculated Tmax obtained from two population pharmacokinetics studies are $1.23 \mathrm{~h} \mathrm{(14)}$ and $1.74 \mathrm{~h} \mathrm{(3).}$

$$
\operatorname{Tmax}=\log (\mathrm{Ka} / \mathrm{Ke}) /(\mathrm{Ka}-\mathrm{Ke})
$$

The baclofen's Tmax indicates a rapid absorption of the compound from the intestinal tract to the bloodstream and should not be confused with the time required to observe an effect. Indeed, some effects may change over time in parallel with plasma concentrations, but this has never been described for baclofen. Unless a direct relationship is described between plasma concentration and a baclofen effect, the Tmax indicates nothing more than a laboratory value. This rapid absorption can be explained by the site of penetration into the digestive tract wall. The upper small intestine completely absorbs baclofen with almost no contribution of the colon (15). This characteristic suggests that baclofen absorption could be modified when prescribed in patients who have undergone a bariatric surgery. Unfortunately, no pharmacokinetic data are currently available in such situation and any prescription to these patients should be made with caution.

Several mechanisms are suggested to explain the ability of a compound to pass through the digestive barrier and to enter into the bloodstream. Depending on its chemical and physical properties, a compound will be absorbed by a passive process, a transporter or both of them. In vitro and in vivo studies have been performed in different species to understand the mechanism of baclofen absorption. Even if more studies are required to fully understand the compound behavior in the digestive wall, some convincing results described that baclofen used more than one intestinal carrier system (16). At least baclofen shares a saturable transport mechanism with essential branched-chain aminoacid (BCAA) such as leucine $(17,18)$. Since aminoacids are a normal component of food, a competitive inhibition could arise. However, a study performed with healthy volunteers under fasting condition vs. a standard meal did not find a significantly influence of food neither on the rate nor on the extent of baclofen absorption (19).

The absolute oral bioavailability has not been evaluated in AUD patients, but in healthy volunteers it was $~ 74 \%$ for $10 \mathrm{mg}$ (8) and $108,85.8$, and $81.2 \%$ for 10,15 , and $20 \mathrm{mg}$, respectively (10). To summarize, following an oral administration the absorption did not seem to be a limiting step for baclofen.

\section{DISTRIBUTION}

Baclofen is $30 \%$ protein bound into the plasma which suggests that protein-binding changes will not be clinically relevant for routine practice (20). In special circumstances such as a baclofen intoxication, where a hemodialysis could be proposed, the protein binding may have an influence.

The mechanism of baclofen in AUD is suggested to be related with its ability to bind to the GABA-B receptor. So, the concern about baclofen distribution in AUD patients is the rate and extent of penetration into the CNS. With a $\log \mathrm{D}$ of -0.96 the lipophilicity of baclofen is insufficient to allow a brain penetration by passive diffusion (21). The baclofen brain entry across the blood-brain-barrier is due to an interaction with the large neutral aminoacid transporter $(22,23)$. However, the resulting influx clearance is counterbalanced by an efficient efflux from the brain through a probenecid-sensitive organic anion transporter 3, OAT3 (SLC22A8) (24, 25). The overall restricted distribution of baclofen in the brain is then the result of an asymmetric transport at the blood-brain-barrier with an efflux transport rate 40 -fold higher than the influx transport rate (25). The fact that baclofen is a substrate of OAT3 remains to be confirmed but recent results corroborate its low apparent permeability coefficient (Caco-2 $P_{\text {app }}: 0.9 \pm 0.710^{-6} \mathrm{~cm} / \mathrm{s}$ ) and its unbound brain/blood ratio (26).

In patients with spastic paresis, a study was designed to elucidate whether the therapeutic responses and the side effects were related to plasma concentrations and CSF levels (27). Four hours after the administration, the authors found CSF levels nine to ten times lower than the plasma concentrations. However, optimal therapeutic responses were obtained at very different levels of plasma and CSF baclofen concentrations and without a clear relationship. The analytical method used for CSF estimation was a limitation resulting in numerous samples below the quantification limit and wasn't able to fully describe the interindividual variation. A recent study used a more efficient quantification analysis to describe the baclofen concentrations in CSF (1). The population wasn't AUD patients but patients with various etiology of severe spasticity. Meanwhile interesting information can be extrapolated to baclofen used in AUD. Before the intra-thecal administration, ten patients were treated with a repeated oral dose of baclofen ranging from 30 to $125 \mathrm{mg}$ per day. The resulting individual trough CSF concentrations were available but not showed in the original article. However, the authors kindly agreed to communicate them allowing the description of the relationship between oral doses and CSF trough concentrations (Figure 1). This figure shows 


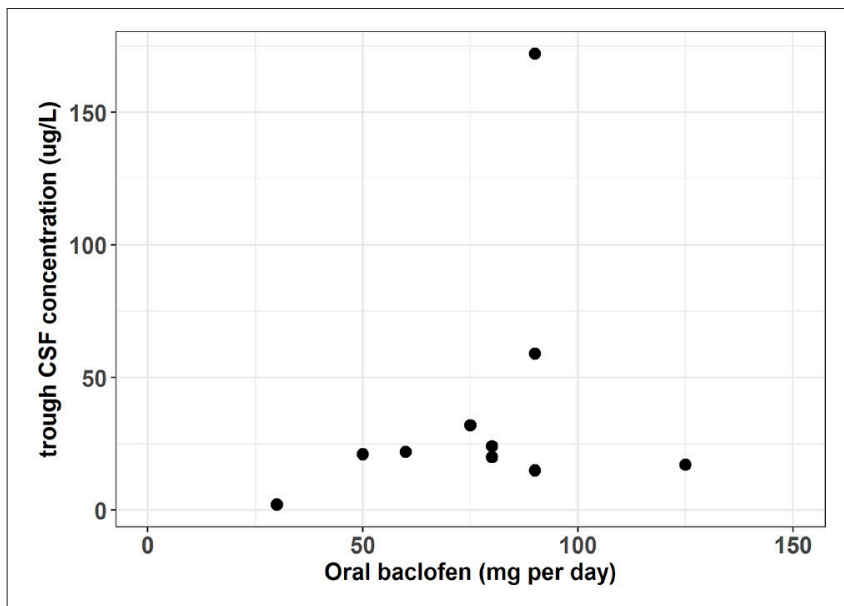

FIGURE 1 | Oral dose vs. trough CSF baclofen concentration in patient with severe spasticity. [From data published by Heetla et al. (1) and individuals CSF trough concentration values kindly communicated by the authors].

that between a dose of $30-125 \mathrm{mg}$ per day the corresponding CSF concentrations seem to vary slightly around $25 \mu \mathrm{g} / \mathrm{L}$. This result suggests that plasma concentration is probably not a good biomarker of baclofen brain exposure. Interestingly, the patients included in this study were recruited on the basis of a severe spasticity which could not be treated sufficiently with an oral therapy. However, following the intrathecal administration, all these patients achieved an adequate spasmolytic effect. The pharmacokinetic/pharmacodynamic (PK/PD) model of spasticity estimated a CSF concentration at $50 \%$ of the maximum effect (EC50) of $194 \mathrm{ug} / \mathrm{L}$ (95\% CI 112, 350), which is higher than the $25 \mathrm{ug} / \mathrm{L}$ obtained with the oral administration. A PK/PD model of baclofen in AUD remains to be identified but the results in patients with spasticity suggest that baclofen brain penetration could be a limiting factor for its efficacy and may explain a large inter-individual variability.

\section{METABOLISM AND ELIMINATION}

A stereoselective metabolic difference between R- and S-baclofen has been recently described (28). In this study no metabolites were observed following an oral administration of the single R-enantiomer. However, the administration of the mixture Rand S- allowed the identification of an oxidative deamination metabolite. This stereoselective metabolism of only the Senantiomer of baclofen is then followed by a glucuronide conjugation. Meanwhile the overall contribution of metabolism is low with $85 \%$ of the dose excreted as unchanged (29). This result may explain that in another study the gammahydroxymetabolite was not detected (12).

Baclofen is mainly cleared through kidneys with a fraction of the dose unchanged in the urine ranging from $65 \%$ (13) to $80.9 \%$ (11). In healthy volunteers a high correlation between the apparent renal clearance of baclofen and the creatinine clearance was described (12). This has been confirmed by a study including four groups of patients with different kidney disease stages (30). The authors found the following significant linear relationship $\left(R^{2}=0.67, p<0.0001\right)$ between baclofen clearance $(\mathrm{CL} / \mathrm{F})$ and

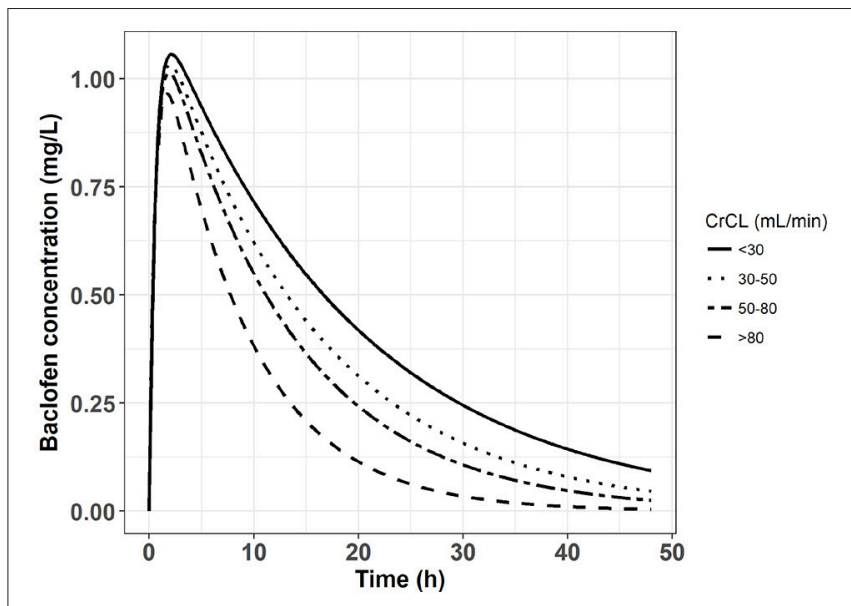

FIGURE 2 | Simulated concentration vs. time profile following an oral dose of $80 \mathrm{mg}$ of baclofen in four groups of patients with different chronic kidney disease stages.

creatinine clearance (CrCL):

$$
C L / F(L / h)=2.25+0.05 \times C r C L(\mathrm{ml} / \mathrm{min})
$$

This result suggests that, if baclofen has to be prescribed in patients with chronic kidney disease, a dose reduction should be applied. Using Equation 2 and a one-compartment model of baclofen described by Imbert et al. (3), it was possible to simulate concentration vs. time profiles with different values of baclofen clearance $(\mathrm{CL} / \mathrm{F})$ depending on the creatinine clearance. The Figure 2 depicts these baclofen simulated concentrations following an oral dose of $80 \mathrm{mg}$ in patients according to different values of creatinine clearance. Meanwhile none of the pharmacokinetic studies performed in AUD patients identified a significant influence of creatinine clearance on baclofen clearance $(3,14,31)$. This surprising result can be explained by the homogeneity of patients included in these studies regarding the renal function.

The baclofen half-life (T1/2) in alcohol-dependent patients with the current immediate release formulation ranged from $3.8 \mathrm{~h}$ (14) to $6.4 \mathrm{~h}$ (3). These values were obtained for doses up to $180 \mathrm{mg}$ per day (3). It's noticeable that during a baclofen overdose an increase of $\mathrm{T} 1 / 2$ is not always observed (32). In such situation, which may lead to comatose, severe respiratory depression and neurotoxicity, hemodialysis has been effective in reversing baclofen toxicity if the patient had a renal insufficiency (33). A gastro-intestinal decontamination with activated charcoal can also be proposed to avoid a persistent intestinal absorption related to a reduced gastro-intestinal mobility or a pharmacobezoar (34).

To conclude on these pharmacokinetic steps, baclofen exhibited no saturation of elimination with clinical doses used and thus no accumulation. However, in patient with chronic kidney disease a decrease of clearance is expected, and the baclofen dosage should be adjusted accordingly. The guidelines for drug dosing regimens in chronic kidney disease deserve further studies. 


\section{DISCUSSION}

Baclofen, as are all drugs, needs to reach its site of action to produce an effect. Because its mechanism of action seems to be related to a binding on the GABA-B receptor in the CNS, the concentrations in plasma are only an indirect marker. It would be more interesting to describe the relationship between an oral dose and CSF concentration, but this kind of study required a catheter located at a spinal level. Other studies such as positron emission tomography imaging could evaluate the baclofen binding to the cerebral GABA-B receptors. For example, we can suggest an imaging study aiming to determine whether patients requiring higher doses and/or patients with poor response correspond to subjects with a lower cerebral binding of baclofen. However, the lack of suitable radiotracers for imaging GABA-B receptors is a current limitation.

Meanwhile a variability in plasma exposure following an oral administration must be evaluated because it is an essential step before the brain penetration. The aim of pharmacokinetic studies is to identify the main source of inter-individual variability such as age, body weight, food, drug-drug interaction, tobacco, renal and hepatic function, genetic polymorphism. However, because the time course of plasma concentration did not necessary follow the time course of an effect, pharmacokinetic studies are not sufficient to establish an optimized dosage. Usually, the increase of plasma concentrations following an administration did not follow the effect onset and likewise the decrease of plasma concentrations presents a different rate than the decrease of the effect. When prescribing baclofen, it's important not to misinterpret Tmax and T1/2: they are not describing the time to effect and the effect disappearance, they are only describing the plasma concentration. Considering the suggested effect of baclofen on craving in AUD, the time to the maximum effect as well as the duration of this effect is still to be described.

Currently only three population pharmacokinetic studies of baclofen have been performed in AUD patients (3, 14, 31). Two studies were based on the same cohort with different objective and population size $(3,31)$. The population were AUD patients, mainly male (43 males, 24 females) from 29 to 68-year-old, with a body weight ranging from 42 to $128 \mathrm{~kg}$, normal renal function and a daily baclofen dose up to $180 \mathrm{mg}$ (3). The second evaluated population present identical demographic and laboratory characteristics (14). These population pharmacokinetic analysis identified a onecompartment model with first-order input and output to describe the time course of plasma concentrations. However, none of these

\section{REFERENCES}

1. Heetla HW, Proost JH, Molmans BH, Staal MJ, van Laar T. A pharmacodynamic-pharmacodynamic model for intrathecal baclofen in patients with severe spasticity. Br J Clin Pharmacol. (2016) 81:101-12. doi: $10.1111 /$ bcp. 12781

2. Rolland B, Paille F, Gillet C, Rigaud A, Moirand R, Dano C, et al. Pharmacotherapy for alcohol dependence: the 2015 recommendations of the French Alcohol Society, issued in partnership with the European Federation studies were able to identify factors explaining inter-individual variability.

The pharmacokinetic parameters were not clearly correlated with age, body weight, sex, smoking status, height, aspartate, aminotransferase, alanine aminotransferase, total bilirubine, gamma-glutamyltransferase, and alkaline phosphatases. Both studies found an influence of creatinine clearance on the baclofen clearance, but this relationship never reached a statistical significance $(14,31)$. Interestingly these studies described a proportional relationship between the oral dose of baclofen and concentrations which did not suggest an accumulation at least up to a daily dose of $180 \mathrm{mg}$ per day.

Concerning putative pharmacokinetic drug-drug interaction, a recent review did not find any of them described in the literature (35). Because baclofen is mainly excreted unchanged in urine, it's unlikely that an inhibition or an induction of its metabolism may have a clinically relevant impact. However, the impact of efflux transporter (OAT3) inhibition in renal tubules and/or in the blood brain barrier deserves an investigation [for a review on OAT family, $(36,37)]$. Several compounds such as probenecid and proton pump inhibitors have been described to inhibit OAT3 transport which increases plasma and brain concentrations (38, 39). It could be of interest to combine baclofen with an OAT3 inhibitor to investigate if brain and plasma concentrations are increased and if it is associated with an improvement of the clinical effect.

\section{CONCLUSION}

Although pharmacokinetic studies already performed in AUD patients described a linear relationship between dose and plasma concentrations, they did not adequately explain the major source(s) of inter-individual variability. Meanwhile caution should be taken if baclofen must be prescribed in patients with chronic kidney disease. A study performed in patients with severe spasticity found no relation between baclofen oral doses and CSF concentrations. This result could partly explain the interindividual variability of the dose required to reach a clinical effect. Indeed, a concern remains on the ability of baclofen to reach the brain with an appropriate rate and extent and new studies are required to investigate this question.

\section{AUTHOR CONTRIBUTIONS}

NS wrote the first draft of the manuscript. NS, BR, and NF contributed to and have approved the final version of the manuscript.

of Addiction Societies. CNS Neurosci Ther. (2016) 22:25-37. doi: 10.1111/cns. 12489

3. Imbert B, Alvarez JC, Simon N. Anticraving effect of baclofen in alcohol-dependent patients. Alcohol Clin Exp Res. (2015) 39:1602-8. doi: 10.1111 /acer.12823

4. Rose AK, Jones A. Baclofen: its effectiveness in reducing harmful drinking, craving, and negative mood. A metaanalysis. Addiction (2018) 113:1396-406. doi: 10.1111/add. 14191 
5. Palpacuer C, Duprez R, Huneau A, Locher C, Boussageon R, Laviolle B. Pharmacologically controlled drinking in the treatment of alcohol dependence or alcohol use disorders: a systematic review with direct and network metaanalyses on nalmefene, naltrexone, acamprosate, baclofen and topiramate. Addiction (2018) 113:220-37. doi: 10.1111/add.13974

6. Reynaud M, Aubin HJ, Trinquet F, Zakine B, Dano C, Dematteis M, et al. A randomized, placebo-controlled study of high-dose baclofen in alcoholdependent patients-the ALPADIR study. Alcohol Alcohol. (2017) 52:439-46. doi: 10.1093/alcalc/agx030

7. Müller CA, Geisel O, Pelz P, Higl V, Krüger J, Stickel A, et al. Highdose baclofen for the treatment of alcohol dependence (BACLAD study): a randomized, placebo-controlled trial. Eur Neuropsychopharmacol. (2015) 25:1167-77. doi: 10.1016/j.euroneuro.2015.04.002

8. Agarwal SK, Kriel RL, Cloyd JC, Coles LD, Scherkenbach LA, Tobin MH, et al. A pilot study assessing pharmacokinetics and tolerability of oral and intravenous baclofen in healthy adult volunteers. J Child Neurol. (2015) 30:37-41. doi: 10.1177/0883073814535504

9. Kowalski P, Chmielewska A, Konieczna L, Oledzka I, Zarzycki PK, Lamparczyk H. The bioequivalence study of baclofen and lioresal tablets using capillary electrophoresis. Biomed Chromatogr. (2004) 18:311-7. doi: 10.1002/bmc.321

10. Schmitz NS, Krach LE, Coles LD, Mishra U, Agarwal SK, Cloyd JC, et al. A randomized dose escalation study of intravenous baclofen in healthy volunteers: clinical tolerance and pharmacokinetics. PMR (2017) 9:743-50. doi: 10.1016/j.pmrj.2016.11.002

11. Shellenberger MK, Groves L, Shah J, Novack GD. A controlled pharmacokinetic evaluation of tizanidine and baclofen at steady state. Drug Metab Dispos. (1999) 27:201-4.

12. Wuis EW, Dirks MJ, Termond EF, Vree TB, Van der Kleijn E. Plasma and urinary excretion kinetics of oral baclofen in healthy subjects. Eur J Clin Pharmacol. (1989) 37:181-4. doi: 10.1007/BF00558228

13. Wuis EW, Dirks MJ, Vree TB, Van der Kleijn E. Pharmacokinetics of baclofen in spastic patients receiving multiple oral doses. Pharm Weekbl Sci. (1990) 12:71-4. doi: 10.1007/BF01970149

14. Chevillard L, Sabo N, Tod M, Labat L, Chasport C, Chevaleyre C, et al. Population pharmacokinetics of oral baclofen at steady-state in alcoholicdependent adult patients. Fundam Clin Pharmacol. (2017) 32:239-48. doi: $10.1111 /$ fcp. 12330

15. Lal R, Sukbuntherng J, Tai EH, Upadhyay S, Yao F, Warren MS, et al. Arbaclofen placarbil, a novel R-baclofen prodrug: improved absorption, distribution, metabolism, and elimination properties compared with R-baclofen. J Pharmacol Exp Ther. (2009) 330:911-21. doi: 10.1124/jpet.108.149773

16. Nácher A, Polache A, Moll-Navarro MJ, Plá-Delfina JM, Merino M. Influence of gamma-aminobutyric acid on baclofen intestinal absorption. Biopharm Drug Dispos. (1994) 15:373-82. doi: 10.1002/bdd.2510150504

17. Cercós-Fortea T, Polache A, Nácher A, Cejudo-Ferragud E, Casabó VG, Merino M. Influence of leucine on intestinal baclofen absorption as a model compound of neutral alpha-aminoacids. Biopharm Drug Dispos. (1995) 16:563-77. doi: 10.1002/bdd.2510160705

18. Moll-Navarro MJ, Merino M, Casabó VG, Nácher A, Polache A. Interaction of taurine on baclofen intestinal absorption: a nonlinear mathematical treatment using differential equations to describe kinetic inhibition models. J Pharm Sci. (1996) 85:1248-54. doi: 10.1021/js9504346

19. Peterson GM, McLean S, Millingen KS. Food does not affect the bioavailability of baclofen. Med J Aust. (1985) 142:689-90.

20. Benet LZ, Hoener B-A. Changes in plasma protein binding have little clinical relevance. Clin Pharmacol Ther. (2002) 71:115-21. doi: $10.1067 / \mathrm{mcp} .2002 .121829$

21. Leisen C, Langguth P, Herbert B, Dressler C, Koggel A, Spahn-Langguth H. Lipophilicities of baclofen ester prodrugs correlate with affinities to the ATP-dependent efflux pump P-glycoprotein: relevance for their permeation across the blood-brain barrier? Pharm Res. (2003) 20:772-8. doi: 10.1023/A:1023437603555

22. van Bree JB, Audus KL, Borchardt RT. Carrier-mediated transport of baclofen across monolayers of bovine brain endothelial cells in primary culture. Pharm Res. (1988) 5:369-71. doi: 10.1023/A:1015959628008

23. van Bree JB, Heijligers-Feijen CD, de Boer AG, Danhof M, Breimer DD. Stereoselective transport of baclofen across the blood-brain barrier in rats as determined by the unit impulse response methodology. Pharm Res. (1991) 8:259-62. doi: 10.1023/A:1015812725011

24. Deguchi Y, Inabe K, Tomiyasu K, Nozawa K, Yamada S, Kimura R. Study on brain interstitial fluid distribution and blood-brain barrier transport of baclofen in rats by microdialysis. Pharm Res. (1995) 12:1838-44. doi: 10.1023/A:1016263032765

25. Ohtsuki S, Asaba H, Takanaga H, Deguchi T, Hosoya K, Otagiri M, et al. Role of blood-brain barrier organic anion transporter 3 (OAT3) in the efflux of indoxyl sulfate, a uremic toxin: its involvement in neurotransmitter metabolite clearance from the brain. J Neurochem. (2002) 83:57-66. doi: 10.1046/j.1471-4159.2002.01108.x

26. Hakkarainen JJ, Jalkanen AJ, Kääriäinen TM, Keski-Rahkonen P, Venäläinen T, Hokkanen J, et al. Comparison of in vitro cell models in predicting in vivo brain entry of drugs. Int J Pharm. (2010) 402:27-36. doi: 10.1016/j.ijpharm.2010.09.016

27. Knutsson E, Lindblom U, Martensson A. Plasma and cerebrospinal fluid levels of baclofen (lioresal) at optimal therapeutic responses in spastic paresis. $J$ Neurol Sci. (1974) 23:473-84. doi: 10.1016/0022-510X(74)90163-4

28. Sanchez-Ponce R, Wang LQ, Lu W, von Hehn J, Cherubini M, Rush R. Metabolic and pharmacokinetic differentiation of STX209 and racemic baclofen in humans. Metabolites (2012) 2:596-613. doi: 10.3390/metabo2030596

29. Faigle JW, Keberle H. The chemistry and kinetics of lioresal. Postgrad Med J. (1972) 48:9-13. doi: 10.1136/pgmj.48.555.59

30. Vlavonou R, Perreault MM, Barrière O, Shink E, Tremblay PO, Larouche R, et al. Pharmacokinetic characterization of baclofen in patients with chronic kidney disease: dose adjustment recommendations. J Clin Pharmacol. (2014) 54:584-92. doi: 10.1002/jcph.247

31. Marsot A, Imbert B, Alvarez JC, Grassin-Delyle S, Jaquet I, Lançon C, et al. High variability in the exposure of baclofen in alcohol-dependent patients. Alcohol Clin Exp Res. (2014) 38:316-21. doi: 10.1111/acer.12235

32. Meulendijks D, Khan S, Koks CH, Huitema AD, Schellens JH, Beijnen JH. Baclofen overdose treated with continuous venovenous hemofiltration. Eur J Clin Pharmacol. (2015) 71:357-61. doi: 10.1007/s00228-014-1802-y

33. Wolf E, Kothari NR, Roberts JK, Sparks MA. Baclofen toxicity in kidney disease. Am J Kidney Dis. (2018) 71:275-80. doi: 10.1053/j.ajkd.2017.07.005

34. Cleophax C, Goncalves A, Chasport C, de Beaugrenier E, Labat L, Declèves X, et al. Usefulness of plasma drug monitoring in severe baclofen poisoning. Clin Toxicol (Phila) (2015) 53:923-4. doi: 10.3109/15563650.2015.1088158

35. Guerzoni S, Pellesi L, Pini LA, Caputo F. Drug-drug interactions in the treatment for alcohol use disorders: a comprehensive review. Pharmacol Res. (2018) 133:65-76. doi: 10.1016/j.phrs.2018.04.024

36. Nigam SK, Bush KT, Martovetsky G, Ahn SY, Liu HC, Richard E, et al. The organic anion transporter (OAT) family: a systems biology perspective. Physiol Rev. (2015) 95:83-123. doi: 10.1152/physrev.00025.2013

37. Campos-Bedolla P, Walter FR, Veszelka S, Deli MA. Role of the blood-brain barrier in the nutrition of the central nervous system. Arch Med Res. (2014) 45:610-38. doi: 10.1016/j.arcmed.2014.11.018

38. Donovan MD, O'Brien FE, Boylan GB, Cryan JF, Griffin BT. The effect of organic anion transporter 3 inhibitor probenecid on bumetanide levels in the brain: an integrated in vivo microdialysis study in the rat. J Pharm Pharmacol. (2015) 67:501-10. doi: 10.1111/jphp.12341

39. Narumi K, Sato Y, Kobayashi M, Furugen A, Kasashi K, Yamada T, et al. Effects of proton pump inhibitors and famotidine on elimination of plasma methotrexate: evaluation of drug-drug interactions mediated by organic anion transporter 3. Biopharm Drug Dispos. (2017) 38:501-8. doi: 10.1002/ bdd. 2091

Conflict of Interest Statement: The authors declare that the research was conducted in the absence of any commercial or financial relationships that could be construed as a potential conflict of interest.

Copyright (c) 2018 Simon, Franchitto and Rolland. This is an open-access article distributed under the terms of the Creative Commons Attribution License (CC BY). The use, distribution or reproduction in other forums is permitted, provided the original author(s) and the copyright owner(s) are credited and that the original publication in this journal is cited, in accordance with accepted academic practice. No use, distribution or reproduction is permitted which does not comply with these terms. 